\title{
Electron Paramagnetic Resonance Study of the Radiation Damage in Trans-Chalcone Single Crystal
}

\author{
B. Caliskan ${ }^{a, *}$ And A. Cengiz Caliskan ${ }^{b}$ \\ ${ }^{a}$ Department of Physics, Faculty of Arts and Science, Pamukkale University, 20070, Kinikli, Denizli, Turkey \\ ${ }^{b}$ Department of Chemistry, Faculty of Science, Gazi University, 06500, Ankara, Turkey \\ (Received June 29, 2018; revised version October 2, 2018; in final form November 27, 2018)

\begin{abstract}
Gamma irradiated trans-chalcone $\left(\mathrm{C}_{15} \mathrm{H}_{12} \mathrm{O}\right)$ single crystals are investigated at $120 \mathrm{~K}$ using electron paramagnetic resonance technique. Trans-chalcone single crystals are irradiated with ${ }^{60} \mathrm{Co}-\gamma$ rays, at room temperature. The EPR spectra of gamma irradiated trans-chalcone single crystals are studied for different orientations of crystals in a magnetic field. The spectra are found to be temperature independent. The structure of the radical produced by $\gamma$-irradiation of a single crystal of trans-chalcone is discussed. The investigation of EPR spectra of gamma-irradiated single crystals of trans-chalcone shows the presence of two trans-chalcone anion radicals. The two trans-chalcone anion radicals are created by the scission of the carbon-oxygen double bond. The reduction of trans-chalcone is identified which is formed by the addition of an electron to oxygen of the formed C-O bond. The principal values of the hyperfine coupling tensors of the unpaired electron and the principal values of the $g$-tensors and direction cosines of the radiation damage centers are determined. The results are found to be in good agreement with the existing literature.
\end{abstract}

DOI: 10.12693/APhysPolA.136.92

PACS/topics: EPR, trans-chalcone $\left(\mathrm{C}_{15} \mathrm{H}_{12} \mathrm{O}\right)$, spectroscopic splitting factor, hyperfine coupling constant, radiation damage center

\section{Introduction}

Free radicals are unstable chemical species with unpaired electrons that are usually highly reactive toward other species. They can be classified as reactive oxygen species (ROS), reactive nitrogen species (RNS), and reactive sulphur species (RSS). Even though free radicals are mainly produced through regular metabolic routes, there are also some external factors that promote their production, including smoking, environmental pollutants, radiation, and drugs, amongst others $[1,2]$. In healthy organisms, there is a delicate balance between the production and the removal of free radicals, which guarantees that they remain in adequate concentrations. However, when this balance is broken these reactive species start producing chemical damages to proteins, lipids, DNA, RNA, and sugars generating the so-called oxidative stress of body cells $[1,3]$. These processes have been associated with several diseases including cardiovascular, liver, neurological, and renal disorders, as well as cancer, auto-immune deficiency, and degenerative disorders associated with ageing, diabetes, obesity, autism, Alzheimer's, Parkinson's, and Huntington's diseases $[1,2,4]$. Although humans have developed different endogenous defence mechanisms to protect cells from the excess of free radicals and to avoid the oxidative stress, often these mechanisms are not enough. Therefore, to increase protection from oxidative damage, dietary supplements with antioxidants are recommended as a way to maintain the concentration of free radicals as low as possible [5].

*corresponding author; e-mail: bcaliskan@pau.edu.tr
Antioxidants are compounds that protect cells against the damaging effects of reactive oxygen species, such as singlet oxygen, superoxide, peroxyl radicals, hydroxyl radicals, and peroxynitrite. An imbalance between antioxidants and reactive oxygen species results in oxidative stress, leading to cellular damage. Oxidative stress has been linked to cancer, ageing, atherosclerosis, ischemic injury, inflammation, and neurodegenerative diseases (Parkinson's and Alzheimer's). Flavonoids may help provide protection against these diseases by contributing, along with antioxidant vitamins and enzymes, to the total antioxidant defense system of the human body. Epidemiological studies have shown that flavonoid intake is inversely related to mortality from coronary heart disease and to the incidence of heart attacks [6].

Flavonoids are polyphenolic compounds that are ubiquitous in nature and are categorized, according to chemical structure, into flavonols, flavones, flavanones, isoflavones, catechins, anthocyanidins, and chalcones. The flavonoids have aroused considerable interest recently because of their potential beneficial effects on human health and they have been reported to have antiviral, antiallergic, antiplatelet, antiinflammatory, antitumor, and antioxidant activities [6].

Chalcones (1,3-diaryl-2-propen-1-ones) are a major class of natural products belonging to the flavonoid family [7]. Chemically, they consist of open-chain flavonoids in which the two aromatic rings are joined by a threecarbon $\alpha, \beta$-unsaturated carbonyl system [8]. The presence of a reactive $\alpha, \beta$ unsaturated carbonyl function in chalcones was found to be responsible for their antimicrobial activity [9]. Furthermore, some metal(II) complexes of chalcones had a variety of biological activities such as anti-HIV, cytotoxic [10, 11], anticancer, 
antifungal, and antibacterial [12] activities. Chalcones are similar to other known antioxidants such as resveratrol, curcumin, and ubiquinone and are the natural precursors of flavonoids and isoflavonoids in higher plants [13-16]. In plants, chalcones protect against UV exposure, pathogens, and insects, and their antioxidant and antiinflammatory properties make them of increasing interest in the treatment of human conditions such as cancer, inflammation and tuberculosis [17-19]. Chalcones exhibit many pharmacological activities including antileishmanial [20], anti-inflammatory [21, 22], anti-mitotic [23], anti-invasive [24], anti-tuberculosis [14], anti-fungal [25], cysteinyl leukotriene receptor-1 antagonist [26], anti-malarial [27, 28], anti-plasmodial, antitumor, immunosuppressive, antioxidant [29], antifibrogenic and modulation of P-glycoprotein-mediated multi-drug resistance [30]. Recent studies have shown that chalcones inhibit cancer cell proliferation in vivo and are effective agents against skin cancers [31, 32]. They also induce apoptosis in various cell types, including breast cancers [33].

The biological activities of chalcones could be closely correlated to their antioxidant potential [34]. The versatility of chalcones has spurred synthesis-based efforts to develop diverse chalcone derivatives with improved activities and physiological stability. As the antioxidant property of chalcones are markedly influenced by the two aryl structures of the chalcone molecule, their structural modification has mainly focused on the variation of the two aryl structures, i.e., the substituents on the two aryl rings and their substitution patterns [35, 36].

In the present study, the radiation damage center in iso trans-chalcone has been characterized by EPR method at $120 \mathrm{~K}$. There is no report in literature on the EPR studies of trans-chalcone single crystals. Therefore, we performed both experimental and simulation study of transchalcone single crystal by EPR spectroscopy method.

\section{Experimental design}

The single crystals of trans-chalcone were grown in the laboratory by slow evaporation of concentrated ethanol solutions. The single crystals crystallized in the orthorhombic space group Pbcn (no. 60), with cell dimensions of $a=10.932(1) \AA, b=11.860(1) \AA, c=$ 17.996(2) $\AA, V=2333.3 \AA^{3}$, and the unit cell contains eight molecules $(Z=8)$ [37].

The single crystals were irradiated with a ${ }^{60} \mathrm{Co} \gamma$-ray source at $1.66 \mathrm{kGy} \mathrm{h}^{-1}$ for $169 \mathrm{~h}$ at room temperature. The samples were exposed to a total absorbed dose of about $280 \mathrm{kGy}$. Gamma irradiation was carried out with SVST Co-60-1 type tote-box gamma radiation source capable of continuous and intermittent irradiation at the Turkish Atomic Energy Authority (TAEK) Sarayköy Nuclear Research and Training Center. The spectra were recorded with a Bruker EMX 081 EPR Spectrometer using $0.2 \mathrm{~mW}$ microwave power. The microwave frequency of the EPR spectrometer is $9.429 \mathrm{GHz}$ for the $a$-axis, $9.429 \mathrm{GHz}$ for the $b$-axis, and $9.438 \mathrm{GHz}$ for the $c$-axis. The modulation frequency of the magnetic field was $100 \mathrm{kHz}$ and the modulation amplitude was $2 \mathrm{G}$. The single crystals were mounted on a goniometer and the spectra were recorded in three mutually perpendicular planes by rotating the crystals around $a, b$, and $c$ axes at $10^{\circ}$ intervals from $0^{\circ}$ to $180^{\circ}$. The low temperature measurements were carried out using a Bruker temperature control unit at $120 \mathrm{~K}$.

\section{Results}

The single crystals of trans-chalcone was irradiated by gamma-rays at room temperature and studied by EPR technique at $120 \mathrm{~K}$. Trans-chalcone single crystals were investigated along three axes perpendicular to each other by EPR spectroscopy. The spectra appear for the other orientations of the magnetic field in three orthogonal planes. The spectra can be interpreted in terms of the spin Hamiltonian

$$
H=\beta \boldsymbol{H} \cdot \hat{g} \cdot \boldsymbol{S}+\boldsymbol{S} \cdot \hat{A} \cdot \boldsymbol{I},
$$

which includes only electronic Zeeman and hyperfine interactions and where $\beta$ is the Bohr magneton, $\boldsymbol{H}$ is the applied magnetic field, $\hat{g}$ is the spectroscopic splitting tensor of the electron, $\hat{A}$ is a hyperfine structure coupling tensor, $\boldsymbol{S}$ is the spin angular momentum of the electron, $\boldsymbol{I}$ is the spin angular momentum of the nucleus. The effects of the chemical medium on unpaired electron spin are measured by the $g$-tensor. The hyperfine structure coupling tensor results from the interaction between the electron spin and the nuclear spin.

The spectra are dependent on the orientation of $\boldsymbol{H}$ in the planes which are perpendicular to each other. The molecular structure of trans-chalcone is shown in Fig. 1. The spectra are found to be temperature independent and paramagnetic centers were attributed to the two trans-chalcone anion radicals. The analysis of the EPR spectra show that the radiation damage center was due to the break of the pi bond in the carbon-oxygen double bond. The structure of two trans-chalcone anion radicals observed in trans-chalcone single crystal is shown in Fig. 2.

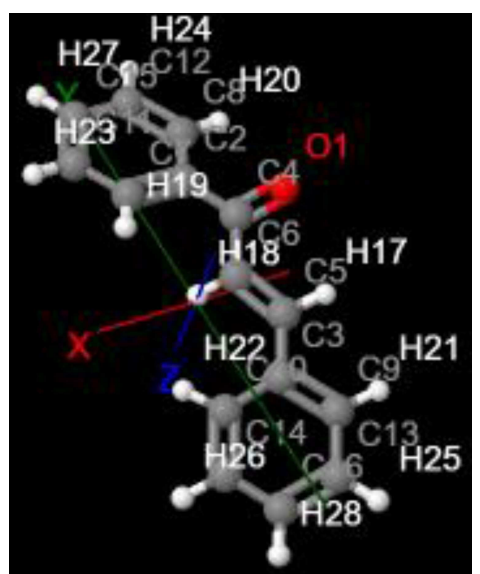

Fig. 1. Molecular structure of trans-chalcone. 


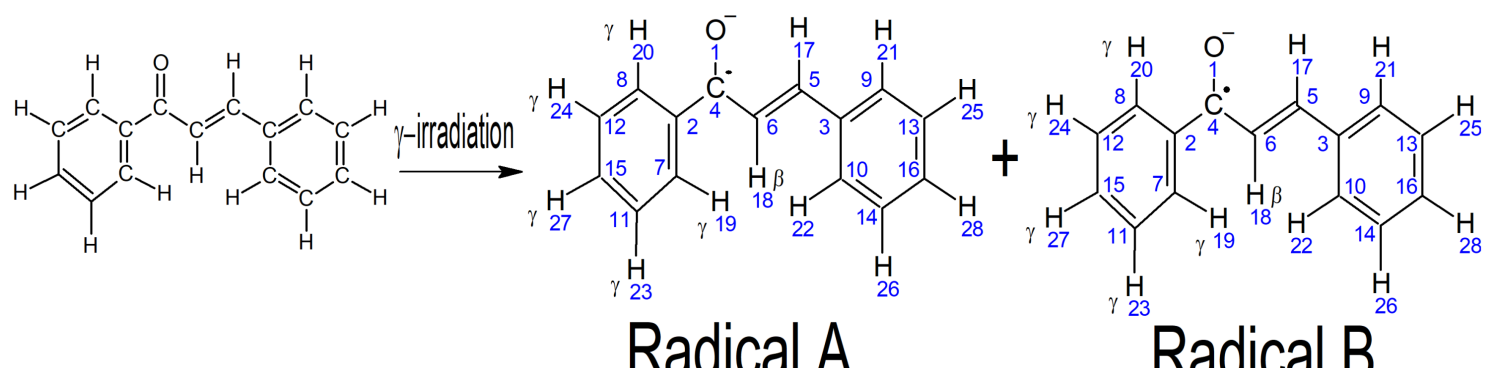

Fig. 2. Structure of two trans-chalcone anion radicals observed in trans-chalcone single crystal.

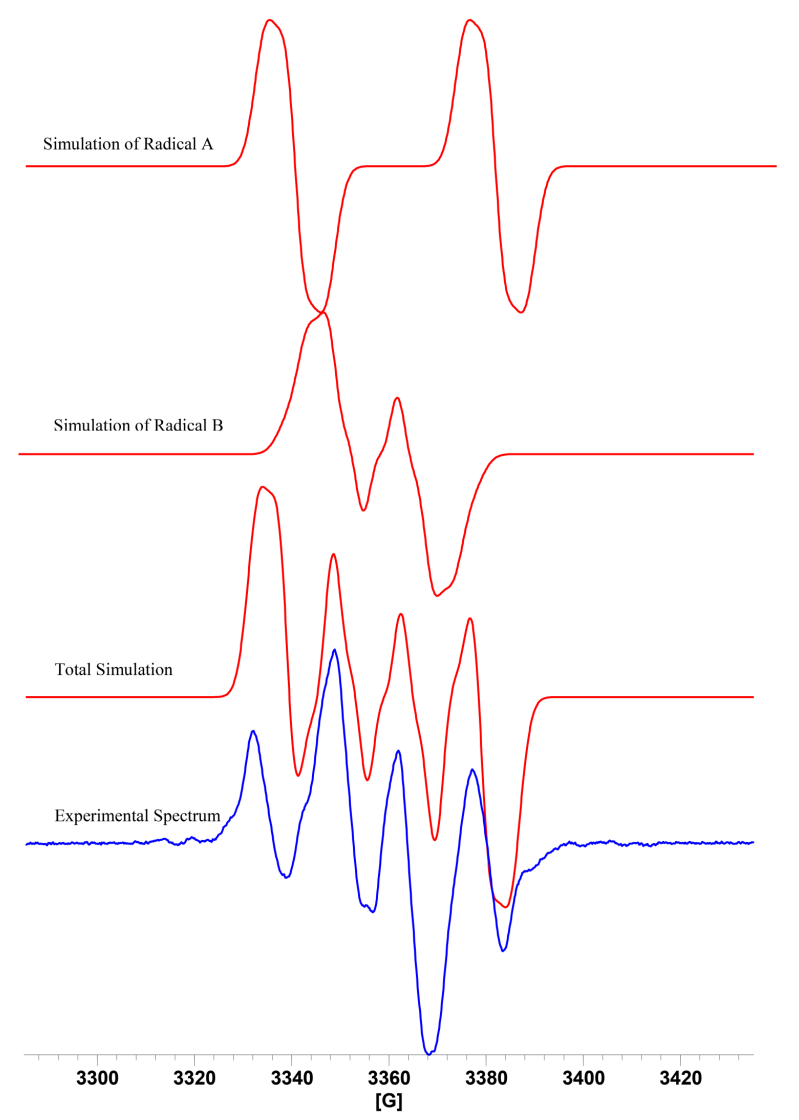

Fig. 3. Experimental and simulated EPR powder spectra of gamma irradiated trans-chalcone single crystal at $120 \mathrm{~K}$.

The simulations of the EPR spectra were carried out using the Win-EPR software. The simulation values of the hyperfine coupling constants of the simulated spectra in Figs. 3-6 are given in Table I. These parameters were slightly modified until a reasonable agreement between simulated and experimental spectra were reached.

The EPR parameters belonging to the two transchalcone anion radicals observed in trans-chalcone are included in Tables II and III. The angular variations of $A$-values and the $g$-value of the radical A in transchalcone single crystal at $120 \mathrm{~K}$ are shown in Figs. 7-9.

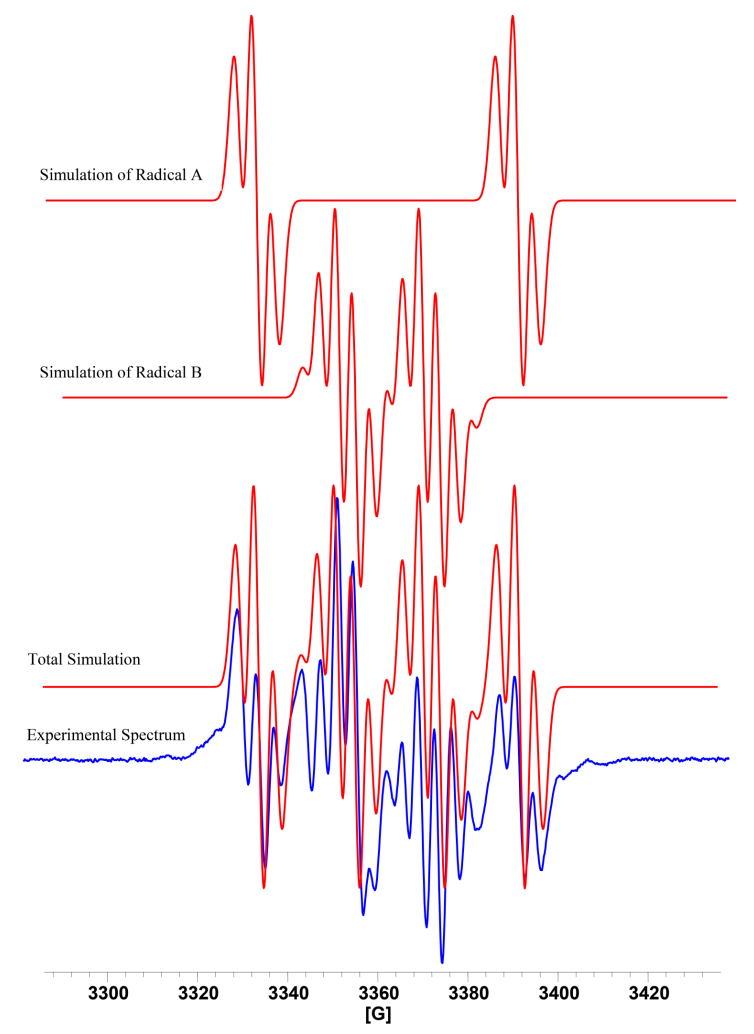

Fig. 4. Experimental and simulated EPR spectra of gamma irradiated trans-chalcone single crystal at $120 \mathrm{~K}$ when the magnetic field is in the $a b$ plane at an angle $0^{\circ}$ towards the axis.

The angular variations of $A$-values and the $g$-value of the radical $\mathrm{B}$ in trans-chalcone single crystal at $120 \mathrm{~K}$ are shown in Figs. 10-12.

The experimental spectra exhibit the superimposition due to the two trans-chalcone anion radicals. Owing to the $\beta$-proton, the spectra exhibit a doublet (1:1) for the radical A and the radical B. Each of the lines (1:1) splits into 6 lines with intensity ratios (1:5:10:10:5:1) due to the five equivalent $\gamma$-protons for the radical $\mathrm{A}$ and the radical B. However, the splits generated by $\gamma$-protons are not apparent due to the line width value. Due to the superimposition, there are differences in the intensity ratios and the number of splits for each spectrum. 


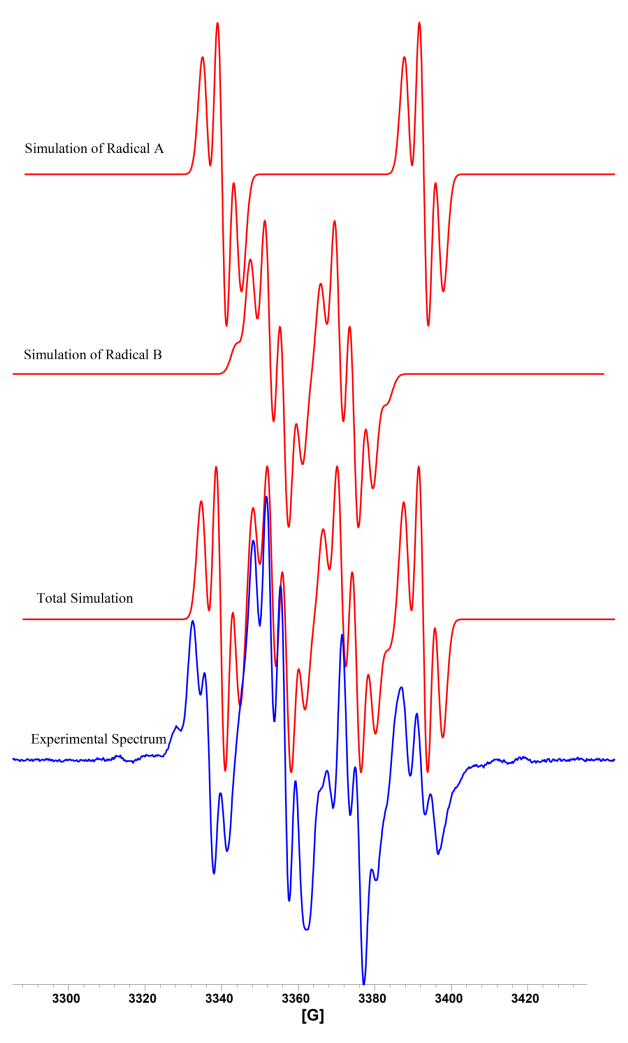

Fig. 5. As in Fig. 4, but for an angle $20^{\circ}$ towards the axis.

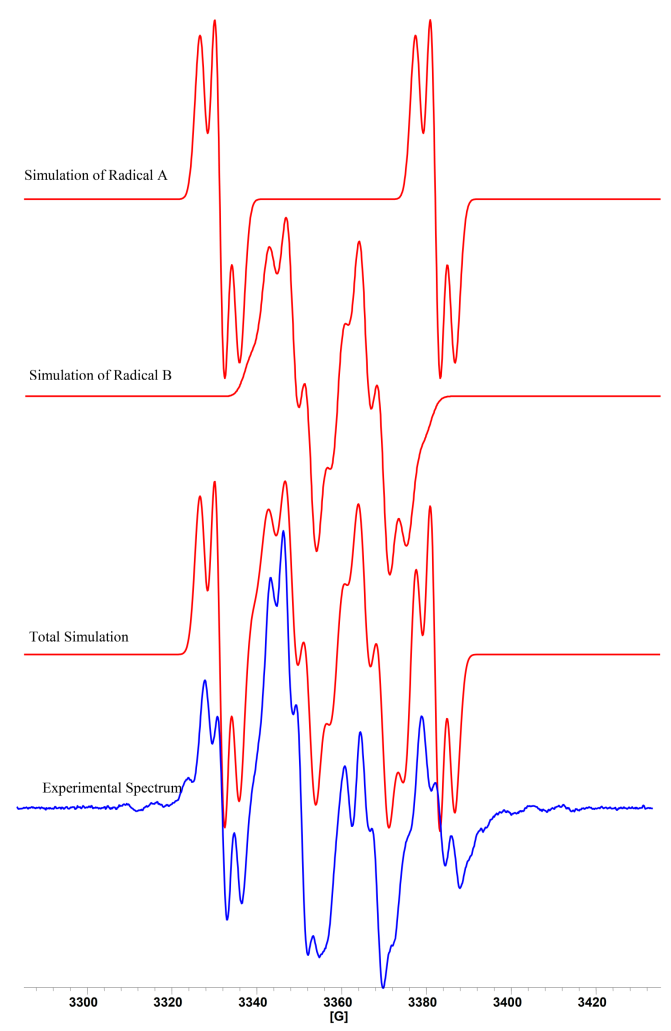

Fig. 6. As in Fig. 4, but when the magnetic field is in the $a c$ plane at an angle $150^{\circ}$ towards the axis.
EPR parameters of simulated spectra

TABLE I

\begin{tabular}{l|l|l}
\hline \hline & \multicolumn{1}{|c|}{ Radical A } & \multicolumn{1}{c}{ Radical B } \\
\hline & $\left(A_{H_{\beta}}\right)_{A}=4 \mathrm{mT}$ & $\left(A_{H_{\beta}}\right)_{B}=1.4 \mathrm{mT}$ \\
Fig. 3 3 & $\left(A_{H_{\gamma}}\right)_{A}=0.412 \mathrm{mT}$ & $\left(A_{H_{\gamma}}\right)_{B}=0.412 \mathrm{mT}$ \\
& center field $=336.318 \mathrm{mT}$ & center field $=336.318 \mathrm{mT}$ \\
& $\nu=9.422 \mathrm{GHz}$ & $\nu=9.422 \mathrm{GHz}$ \\
& line width $=0.49 \mathrm{mT}$ & line width $=0.49 \mathrm{mT}$ \\
\hline \multirow{5}{*}{ Fig. 4 } & $\left(A_{H_{\beta}}\right)_{A}=5.645 \mathrm{mT}$ & $\left(A_{H_{\beta}}\right)_{B}=1.889 \mathrm{mT}$ \\
& $\left(A_{H_{\gamma}}\right)_{A}=0.357 \mathrm{mT}$ & $\left(A_{H_{\gamma}}\right)_{B}=0.357 \mathrm{mT}$ \\
& cold &
\end{tabular}

Fig. 4 center field $=336.318 \mathrm{mT}$ center field $=336.318 \mathrm{mT}$ $\nu=9.422 \mathrm{GHz} \quad \nu=9.422 \mathrm{GHz}$

line width $=0.28 \mathrm{mT} \quad$ line width $=0.28 \mathrm{mT}$

\begin{tabular}{lll}
\hline$\left(A_{H_{\beta}}\right)_{A}=5.127 \mathrm{mT}$ & $\left(A_{H_{\beta}}\right)_{B}=1.769 \mathrm{mT}$ \\
$\left(A_{H_{\gamma}}\right)_{A}=0.359 \mathrm{mT}$ & $\left(A_{H_{\gamma}}\right)_{B}=0.358 \mathrm{mT}$
\end{tabular}

Fig. 5 center field $=336.319 \mathrm{mT}$ center field $=336.319 \mathrm{mT}$ $\nu=9.422 \mathrm{GHz} \quad \nu=9.422 \mathrm{GHz}$

\begin{tabular}{l|l|l} 
& line width $=0.28 \mathrm{mT}$ & line width $=0.28 \mathrm{mT}$ \\
\hline & $\left(A_{H_{\beta}}\right)_{A}=5.078 \mathrm{mT}$ & $\left(A_{H_{\beta}}\right)_{B}=1.713 \mathrm{mT}$ \\
$\left(A_{H_{\gamma}}\right)_{A}=0.333 \mathrm{mT}$ & $\left(A_{H_{\gamma}}\right)_{B}=0.408 \mathrm{mT}$
\end{tabular}

Fig. 6 center field $=336.319 \mathrm{mT}$ center field $=336.318 \mathrm{mT}$ $\nu=9.41 \mathrm{GHz} \quad \nu=9.422 \mathrm{GHz}$

line width $=0.29 \mathrm{mT} \quad$ line width $=0.405 \mathrm{mT}$

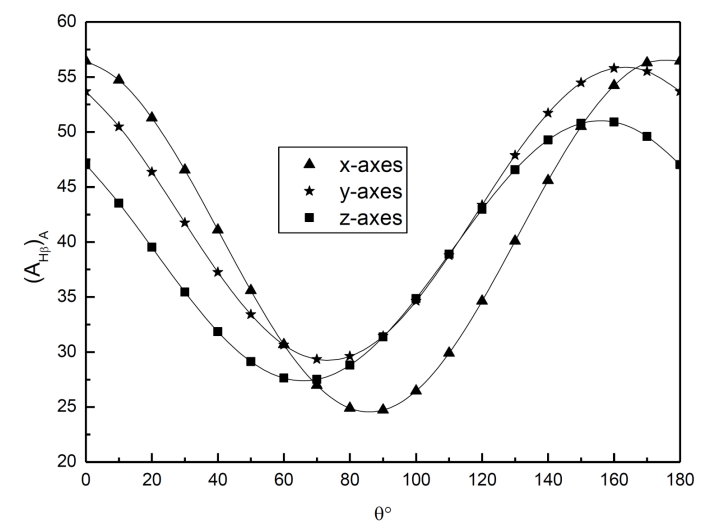

Fig. 7. Angular variation of the $\left(A_{H_{\beta}}\right)$-tensor of the radical A observed in trans-chalcone single crystals at $120 \mathrm{~K}$ (the solid lines in the figure are the theoretical fit values obtained by least squares method).

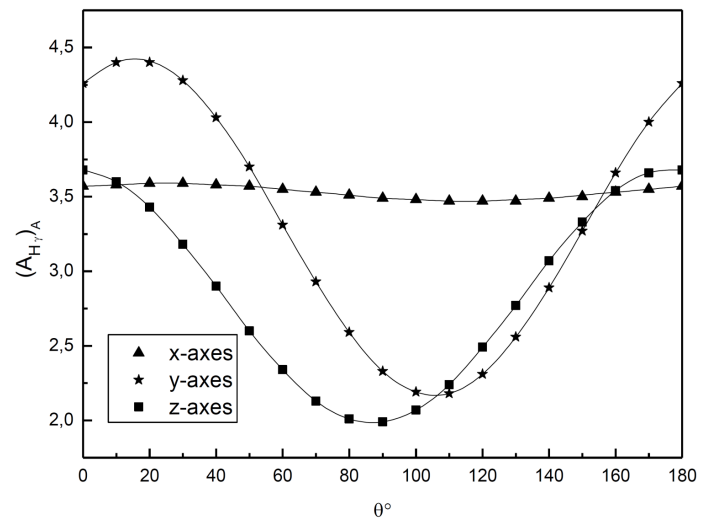

Fig. 8. As in Fig. 7, but for the $\left(A_{H_{\gamma}}\right)$-tensor. 
TABLE II

The EPR parameters of radical A observed in transchalcone at $120 \mathrm{~K}$. (Note: The errors are estimated to be \pm 0.00005 and $\pm 0.005 \mathrm{mT}$ for all the calculated $g$ - and $A$-values, respectively.)

\begin{tabular}{c|l|ccc}
\hline \hline $\begin{array}{c}\text { Radical } \\
\text { parameters } \\
\text { (radical A) }\end{array}$ & $\begin{array}{c}\text { Principal } \\
\text { values }\end{array}$ & \multicolumn{3}{|c}{ Direction cosines } \\
\hline \multirow{5}{*}{$\left(A_{H_{\beta}}\right)_{A}[\mathrm{mT}]$} & $A_{x x}=5.199$ & 0.744056 & -0.314389 & 0.589525 \\
& $A_{y y}=4.365$ & -0.299990 & 0.631213 & 0.715246 \\
& $A_{z z}=2.611$ & -0.596981 & -0.709035 & 0.375344 \\
& $a_{a v}=4.058$ & & & \\
\hline \multirow{5}{*}{$\left(A_{H_{\gamma}}\right)_{A}[\mathrm{mT}]$} & $A_{x x}=0.371$ & 0.780755 & 0.079558 & -0.619752 \\
& $A_{y y}=0.357$ & -0.165974 & 0.982635 & -0.082949 \\
& $A_{z z}=0.242$ & 0.602391 & 0.167626 & 0.780402 \\
& $a_{a v}=0.323$ & & & \\
\hline$g_{A}$ & $g_{x x}=2.00841$ & 0.080783 & 0.896141 & -0.436356 \\
& $g_{y y}=2.00592$ & -0.989779 & 0.020503 & -0.141131 \\
& $g_{z z}=2.00378$ & -0.117527 & 0.443297 & 0.888637 \\
& $g_{a v}=2.00604$ & & &
\end{tabular}

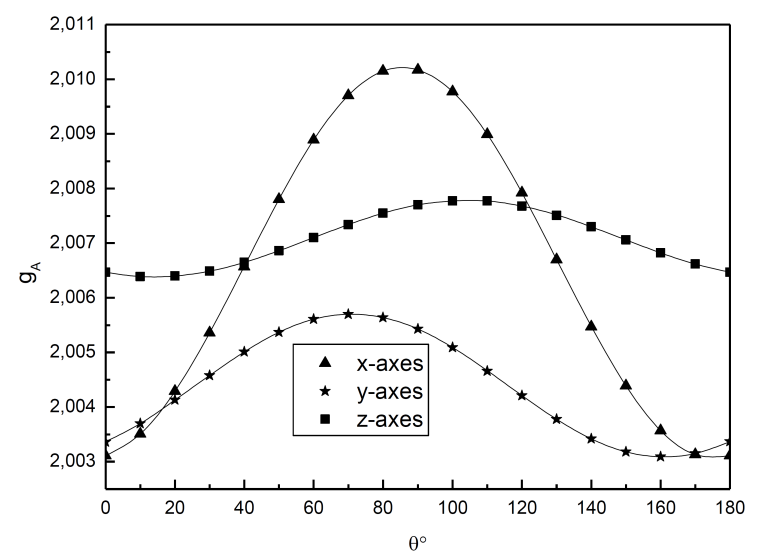

Fig. 9. As in Fig. 7, but for the $g$-tensor.

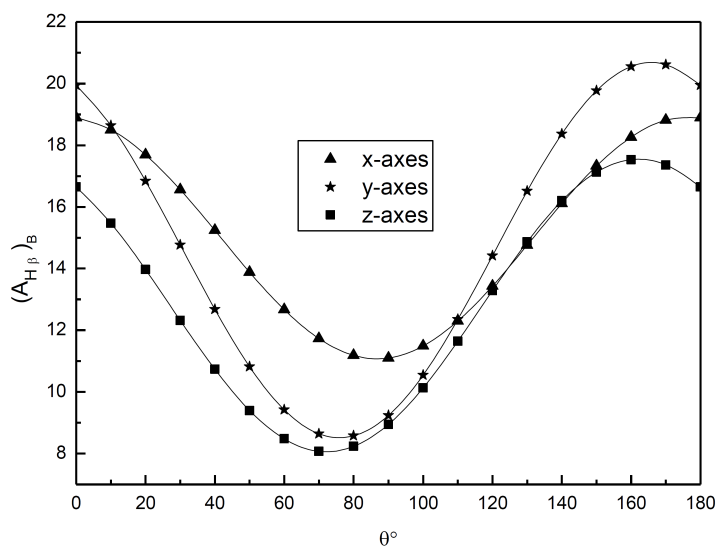

Fig. 10. Angular variation of the $\left(A_{H_{\beta}}\right)$-tensor of the radical $\mathrm{B}$ observed in trans-chalcone single crystals at $120 \mathrm{~K}$ (the solid lines in the figure are the theoretical fit values obtained by least squares method).
TABLE III

The EPR parameters of the radical B observed in transchalcone at $120 \mathrm{~K}$. (Note: The errors are estimated to be \pm 0.00005 and $\pm 0.005 \mathrm{mT}$ for all the calculated $g$ - and $A$-values, respectively.)

\begin{tabular}{c|l|ccc}
\hline \hline $\begin{array}{c}\text { Radical } \\
\text { parameters } \\
\text { (radical B) }\end{array}$ & $\begin{array}{c}\text { Principal } \\
\text { values }\end{array}$ & \multicolumn{3}{|c}{ Direction cosines } \\
\hline \multirow{3}{*}{$\left(A_{H_{\beta}}\right)_{B}[\mathrm{mT}]$} & $A_{x x}=1.802$ & 0.765021 & -0.096821 & 0.636686 \\
& $A_{y y}=1.468$ & -0.363219 & 0.751521 & 0.550716 \\
& $A_{z z}=0.999$ & -0.531804 & -0.652566 & 0.539762 \\
& $a_{a v}=1.423$ & & & \\
\hline \multirow{3}{*}{$\left.A_{H_{\gamma}}\right)_{B}[\mathrm{mT}]$} & $A_{x x}=0.433$ & 0.835857 & 0.071607 & -0.544257 \\
& $A_{y y}=0.312$ & -0.546341 & 0.012025 & -0.837476 \\
& $A_{z z}=0.287$ & -0.053424 & 0.997360 & 0.049173 \\
& $a_{a v}=0.344$ & & & \\
\hline$g_{B}$ & $g_{x x}=2.00972$ & 0.341671 & 0.780920 & -0.522901 \\
& $g_{y y}=2.00742$ & -0.923418 & 0.175457 & -0.341341 \\
& $g_{z z}=2.00528$ & -0.174813 & 0.599483 & 0.781064 \\
& $g_{a v}=2.00747$ & & &
\end{tabular}

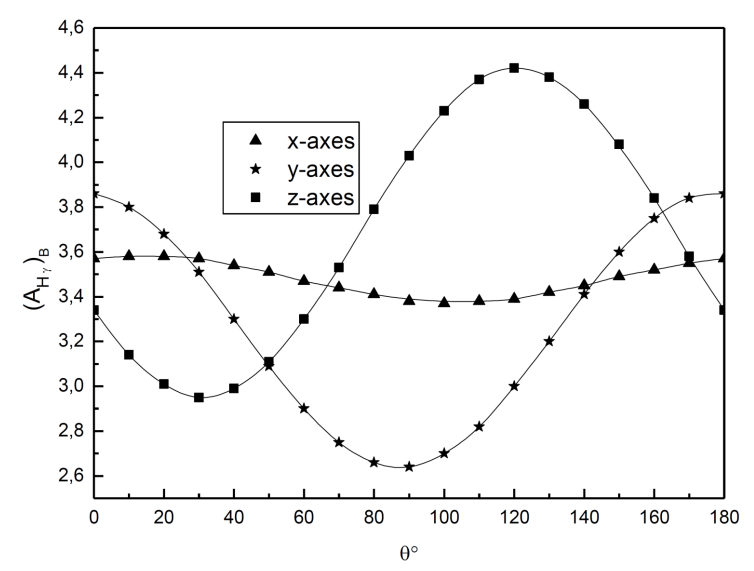

Fig. 11. As in Fig. 10, but for the $\left(A_{H_{\gamma}}\right)$-tensor.

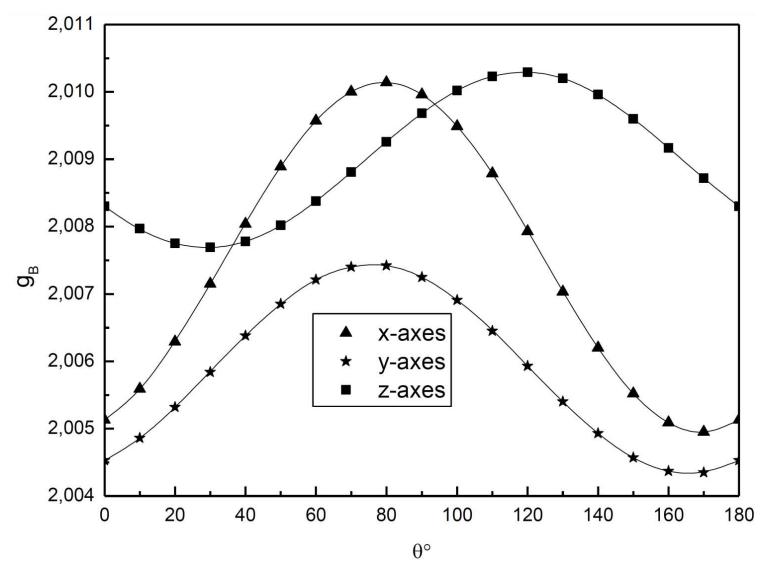

Fig. 12. As in Fig. 10, but for the $g$-tensor. 


\section{Discussion}

Chalcones are important precursors in the biosynthesis of flavones and flavanones, and are usually synthesized from acetophenones and benzaldehydes via the ClaisenSchmidt condensation, using base in a polar solvent [38]. Basic structure of chalcones includes two aromatic rings linked by a $\beta$-unsaturated carbonyl group, a unique template associated with very diverse application [39]. Due to presence of reactive keto and vinylenic group; chalcone and their analogue have been reported to be antioxidant [40-42]. Chalcones possess conjugated double bonds and a completely delocalized $\pi$-electron system on both benzene rings. Molecules possessing such system have relatively low redox potentials and have a greater probability of undergoing electron transfer reactions [38]. Several oxygenated chalcones, hydroxyl chalcones, bis-chalcones, and quinolinyl chalcone analogs exhibit anti-malarial activity [43, 44]. Some chalcones also demonstrate their ability to block voltage-dependent potassium channels [45]. These limited yet interesting studies clearly suggest the beneficial effects of chalcones and other derivatives in human health and diseases. Xia and coworkers were the first to demonstrate improved anti-proliferative activity of chalcones with substituted amino groups [46]. LeBlanc et al. have shown that methoxylated chalcones with a 3'-amino group had submicromolar $\mathrm{IC}_{50}$ values against murine melanoma B16 cells [47]. They postulated that the amino function would be protonated at low $\mathrm{pH}$ environment normally encountered in tumors. The electron withdrawing effect of the protonated ammonium function would enhance the electrophilicity of the $\beta$-carbon in the enone linkage, hence increasing its reactivity as a Michael acceptor [48].

Liquorice has been used in China for the treatment of gastric and duodenal ulcers, bronchial asthma, Addison's disease, poisoning by food and drugs and skin disease such as eczema and urticaria [49]. The liquorice extracts contains a chalcone, viz. isoliquritigenin, which is currently in use as a phosphodiesterase III inhibitor for the treatment of cardiovascular diseases [50]. Another chalcone compound called "butein" has also been used for treatment of pain, thrombotic disease, stomach cancer, and parasitic infection as well as a food additive [51]. Induction of phase 2 enzymes (e.g., glutathione transferases, NAD $(\mathrm{P}) \mathrm{H}$ :quinone reductase, glucuronosyltransferases, epoxide hydrolase) is a major strategy for reducing the susceptibility of animal cells to neoplasia. The Michael reaction acceptors (i.e., olefins or acetylenes that are conjugated to electron-withdrawing groups) are a major group of inducers of induction of phase 2 enzymes. The potencies of these compounds in inducing $\mathrm{NAD}(\mathrm{P}) \mathrm{H}$ :quinone reductase activity in murine hepatoma cells paralleled their Michael reaction acceptor activity [52]. Chalcones belong to this wide class of compounds. It has been published that the free radicalscavenging capacity of several quinone reductase inducers show good correlation with their potencies as inducers of phase 2 enzymes, suggesting that the regulation of phase 2 enzymes may involve both the Michael reaction reactivity and radical quenching mechanism [53]. On the other hand, it seems noteworthy that a phenolic aryl ketone grouping is a common feature of many biologically active compounds [54].

Recently the substituent effects on the reduction potentials of a large numbers of chalcone derivatives have been studied. The reduction behavior of different substituted chalcone derivatives was investigated using voltammetric techniques such as cyclic voltammetry and differential pulse voltammetry [55]. Zuman et al. [56] informed on the polarographic reduction of chalcone in aqueous medium finding a radical anion which is protonated with an approximate pK value of 10.2. Further cyclic voltammetric studies [57] carried out in dimethyl sulfoxide (DMSO) were consistent with a mechanism involving the reduction of the $\alpha, \beta$-unsaturated ketone to its radical anion followed by irreversible dimerization. Previously, there were reports of a direct correlation between the natural bond orbital (NBO) stabilization energy $\Delta E_{i j}^{(2)}$,and ${ }^{1} \mathrm{H}-\mathrm{NMR}$ chemical shift of the hydrogen engaged in the intramolecular hydrogen bonds (IHB) in a series of hydroquinones [58]. A similar behaviour has been found for these chalcone derivatives. The stabilization energies for the IHBs correlate with the reduction potential, which indicates that the strength of IHB has a strong influence in the capability of these chalcones to capture an extra electron. A comparison with ${ }^{1} \mathrm{H}-\mathrm{NMR}$ data shows that NBO energy is a good parameter to measure the strength of the IHB. Stabilization energies for the IHBs point in the same direction of reduction potentials, and they present a good semi-quantitative correlation $\left(R^{2}=0.90\right)$, which indicates that the strength of IHB has a significant influence in the reduction potential of these chalcones [59].

In other work, the formation of a radical anion and radical dianion by the electrolysis of chalcone in anhydrous dimethylformamide was reported [60]. Some Russian authors $[61,62]$ proposed that in the context of reduction of chalcones involved, the first electron attack takes place on the carbonyl group and the free radical formed undergoes isomerization into another free radical which is further reduced or can be converted into a dimer. Three 2'-hydroxy chalcone derivatives (2,3DIMECHA, 2,4-DIMECHA, 2,5-DIMECHA) are electrochemically reduced to the radical anion by a reversible one electron transfer followed by a chemical dimerization reaction [63]. From the analysis of the adiabatic electron affinities (AEAs), the vertical electron affinities (VEAs), and the vertical detachment energies (VDEs), it has been found that all chalcones can take an electron and form a stable radical anion [59]. The formation of substituents having positive mesomeric and inductive electronic effects increases the energy level HOMO, LUMO, the energy gap of the chalcones [64], and the reducing properties of the chalcones $[64,65]$. The computed HOMO-LUMO gap, the ionization potential (IP), 
the electron affinity (EA) [64, 65], the electronegativity, the electrophilicity, and the permanent dipole moment values [64] confirm that chalcones exhibits low hardness and thus a tendency to readily deprotonate to form chalcone deprotonated anion, which is stabilized by extension of conjugation [65]. A good correlation is found between the above listed values and experimental antioxidant activity $[64,65]$. The metal chelating properties of chalcones support the assumption that these chalcones may play an important role in metal over load diseases. Chalcone will certainly prove beneficial for the cell protection from the radical and metal induced deleterious effects. Chalcone derivatives results show good correlation between electronegativity of the substituent groups and the hydroxyl (-O2'-H2') BDE (bond dissociation energy), where BDE decreases as the electronegativity of the substituent increases [64].

The spin density on each atom in a molecule is an important parameter to characterize the stability of the free radicals because the energy of a radical can be efficiently decreased if the unpaired electron is highly delocalized through a conjugative system [66]. The role of C7, C8-double bond in conjugation with a = O9' carbonyl function in the chalcone are responsible for the unpaired electron delocalization and stabilizing radical [67]. The spin density difference on $=$ O9' oxygen is 0.021 and 0.022 for $4 \mathrm{MeC}$ and $4 \mathrm{ClC}$, respectively. Similar effect is observed in most of the atoms in the chalcone molecule [64]. The reducibility of the carbonyl function in chalcones and its relationship to biological activity has been investigated [68]. In quantitative structure-activity relationships (QSAR), the reducibility of the carbonyl function serves as an indirect indicator of the electron density on the carbonyl function. A readily reducible carbonyl group would imply that the carbonyl carbon is electron-deficient. Electron delocalization along the $\alpha$, $\beta$-unsaturated chain would render the $\beta$-carbon electron deficient and accordingly, more susceptible to attack by thiols and other nucleophiles. Thus, one would expect a relationship between the reducibility of the carbonyl bond (for example, measured in terms of reduction peak potentials in cyclic voltammetry) and the susceptibility to nucleophilic attack at the $\beta$-carbon. On the other hand, in vivo reduction of the carbonyl group to an alcohol is unlikely to predominate, as seen from the in vitro biotransformation of 4-dimethylamino-4' (imidazol-1-yl) chalcone [69].

The resonance structure of trans-chalcone is formed by the placement of the odd electron on the carbon atom in the carbonyl group. The radical mechanism of the trans-chalcone is the same as the radical mechanisms of 3-nitroacetophenone [70], hydroquinone [71], potassium hydroquinone monosulfonate [72], semiquinone, tetrachlorosemiquinone [71, 73], tetrafluoro $p$-semiquinone [74], succinic anhydride [75], dihydroxyfumaric acid, ascorbic acid, and reductic acid [71, 73]. Molecular oxygen is the electron acceptor, as demonstrated by spin trapping [76]. Quinones can be reduced in a one electron step to the semiquinone radical ion $[73,77,78]$. These semiquinones are moderately stable. Their stability is explained by resonance forms in which the odd electron is placed on the ring carbon atoms as well as on both oxygens. The $p$-semiquinones are the reaction intermediates in the general quinonehydroquinone oxidation-reduction system [79]. The negative charge and the unpaired electron system are delocalized over the $\pi$-electron system for the tetrafluoro $p$-semiquinone anion [74].

EPR analysis of gamma-irradiated trans-chalconene was performed at $120 \mathrm{~K}$. Two anion radicals were observed as radical $A$ and radical $B$, respectively. In radical $\mathrm{A}$ and radical $\mathrm{B}$, the hyperfine splitting of beta- and gamma-protons is anisotropic. For the radical A, the average values of the $g$-factor and the hyperfine coupling constants were obtained as $g_{A}=2.00604,\left(a_{H_{\beta}}\right)_{A}=$ $4.058 \mathrm{mT}$, and $\left(a_{H_{\gamma}}\right)_{A}=0.323 \mathrm{mT}$, respectively. For the radical $\mathrm{B}$, the average values of the $g$-factor and the hyperfine coupling constants were obtained as $g_{B}=$ 2.00747, $\left(a_{H_{\beta}}\right)_{B}=1.423 \mathrm{mT}$, and $\left(a_{H_{\gamma}}\right)_{B}=0.344 \mathrm{mT}$, respectively. These values are also in agreement with the literature values given for these radicals. The average value of the $\left(A_{H_{\beta}}\right)_{A}$ tensor of the radical $\mathrm{A}$ in the present study are close to the values in the previous study [80]. Similarity, the average value of the $\left(A_{H_{\beta}}\right)_{B}$ tensor of the radical $\mathrm{B}$ in the present study are close to the values in the previous study [81]. The average values of the $\left(A_{H_{\gamma}}\right)_{A}$ and the $\left(A_{H_{\gamma}}\right)_{B}$ tensors of the two radical anions in the present study are close to the values in previous study $[72,82]$. The average values of $g_{A}$ and $g_{B}$-value of this compound are in accordance with the literature $[72,83]$.

Although the two anion radicals in the sample are identical in structure, these radicals differ in terms of the hyperfine coupling constants of the beta protons. In radical A, the isotropic value of the hyperfine coupling constant of the beta proton was $4.058 \mathrm{mT}$, whereas in radical $\mathrm{B}$ the isotropic value of the hyperfine coupling constant of the beta proton was $1.423 \mathrm{mT}$. The isotropic values of the gamma protons of both radicals were found to be close to $0.3 \mathrm{mT}$.

\section{Conclusions}

In this study, the structure of the radical formed from $\gamma$-irradiated trans-chalcone single crystal is shown, after being damaged at room temperature by gamma irradiation. The EPR spectra analysis indicates the presence of the two trans-chalcone anion radicals. The radicals are stable. The two trans-chalcone anion radicals (radical A and radical B), which are created by the scission of the carbon-oxygen double bond, are formed in the gamma-irradiated trans-chalcone single crystal. The radiation damage centers are discussed using the spin Hamiltonian parameters obtained from the spectra. The hyperfine coupling constants and the $g$-values are anisotropic. These values are verified by computer simulation. 


\section{Acknowledgments}

This work was supported by the BAP of Pamukkale University (grant number 2012FBE037).

\section{References}

[1] L.A. Pham-Huy, H. He, C. Pham-Huy, Int. J. Biomed. Sci. 4, 89 (2008).

[2] B. Halliwell, "Free radicals and other reactive species in disease", in: Encyclopedia of Life Sciences, 2001, p. 1.

[3] V. Lobo, A. Patil, A. Phatak, N. Chandra, Pharmacogn. Rev. 4, 118 (2010).

[4] T.M. Florence, N.Z. Aust, J. Ophthalmol. 23, 3 (1995).

[5] P.G. Pietta, J. Nat. Prod. 63, 1035 (2000).

[6] S. Mondal, Screening of Bioactive Compounds from Cucurbitaceae Family Edible Plants of BangladeshCucurbita Pepo Linn: A Case Study, Anchor Academic Publishing, Hamburg 2017, p. 47.

[7] K.J. Hwang, H.S. Kim, I.C. Han, B.T. Kim, Bull. Kor. Chem. Soc. 33, 2585 (2012).

[8] S. Syam, S.I. Abdelwahab, M.A. Al-Mamary, S. Mohan, Molecules 17, 6179 (2012).

[9] Y.R. Prasad, A.L. Rao, R. Rambabu, E-J. Chem. 5, 461 (2008).

[10] L. Mishra, R. Sinha, H. Itokawa, K.F. Bastow, Y. Tachibana, Y. Nakanishi, N. Kilgore, K.H. Lee, Bioorg. Med. Chem. 9, 1667 (2001).

[11] R. Prajapati, S.K. Dubey, R. Gaur, R.K. Koiri, B.K. Maurya, S.K. Trigun, L. Mishra, Polyhedron 29, 1055 (2010).

[12] M. Muthukumar, P. Viswanathamurthi, J. Coord. Chem. 63, 1263 (2010).

[13] N.K. Sahu, S.S. Balbhadra, J. Choudhary, D.V. Kohli, Curr. Med. Chem. 19, 209 (2012).

[14] Y.M. Lin, Y. Zhou, M.T. Flavin, L.M. Zhou, W. Nie, F.C. Chen, Bioorg. Med. Chem. 10, 2795 (2002).

[15] J. Mojzis, L. Varinska, G. Mojzisova, I. Kostova, L. Mirossay, Pharmacol. Res. 57, 259 (2008).

[16] F.D. Piaz, A. Braca, M.A. Belisario, N. De Tommasi, Curr. Med. Chem. 17, 479 (2010).

[17] M.L.F. Ferreyra, S.P. Rius, P. Casati, Front. Plant Sci. 3, 1 (2012).

[18] Z. Nowakowska, E-J. Med. Chem. 42, 125 (2007).

[19] N. Yadav, S.K. Dixit, A. Bhattacharya, L.C. Mishra, M. Sharma, S.K. Awasthi, V.K. Bhasin, Chem. Biol. Drug Des. 80, 340 (2012).

[20] S.F. Nielsen, S.B. Christensen, G. Cruciani, A. Kharazmi, T. Liljefors, J. Med. Chem. 41, 4819 (1998).

[21] H.H. Ko, L.T. Tsao, K.L. Yu, C.T. Liu, J.P. Wang, C.N. Lin, Bioorg. Med. Chem. 11, 105 (2003).

[22] F. Herencia, M.L. Ferrándiz, A. Ubeda, J.N. Domínguez, J.E. Charris, G.M. Lobo, M.J. Alcaraz, Bioorg. Med. Chem. Lett. 8, 1169 (1998).
[23] S. Ducki, R. Forrest, J.A. Hadfield, A. Kendall, N.J. Lawrence, A.T. McGown, D. Rennison, Bioorg. Med. Chem. Lett. 8, 1051 (1998).

[24] S. Mukherjee, V. Kumar, A.K. Prasad, H.G. Raj, M.E. Bracke, C.E. Olsen, S.C. Jain, V.S. Parmar, Bioorg. Med. Chem. 9, 337 (2001).

[25] S.N. López, M.V. Castelli, S.A. Zacchino, J.N. Domínguez, G. Lobo, J. Charris-Charris, J.C.G. Cortés, J.C. Ribas, C. Devia, A.M. Rodríguez, R.D. Enriz, Bioorg. Med. Chem. 9, 1999 (2001).

[26] M.E. Zwaagstra, H. Timmerman, M. Tamura, T. Tohma, Y. Wada, K. Onogi, M.Q. Zhang, J. Med. Chem. 40, 1075 (1997).

[27] R. Li, G.L. Kenyon, F.E. Cohen, X. Chen, B. Gong, J.N. Domínguez, E. Davidson, G. Kurzban, R.E. Miller, E.O. Nuzum, P.J. Rosenthal, J.H. McKerrow, J. Med. Chem. 38, 5031 (1995).

[28] M. Liu, P. Wilairat, M.L. Go, J. Med. Chem. 44 4443 (2001).

[29] M.L. Go, X. Wu, X.L. Liu, Curr. Med. Chem. 12, $481(2005)$.

[30] F. Bois, A. Boumendjel, A.M. Mariotte, G. Conseil, P.A. Di, Bioorg. Med. Chem. 7, 2691 (1999).

[31] Y. Satomi, Int. J. Cancer 55, 506 (1993).

[32] S. Yamamoto, E. Aizu, H. Jiang, T. Nakadate, I. Kiyoto, J.C. Wang, R. Kato, Carcinogenesis 12, 317 (1991).

[33] C.A. Calliste, J.C. Le Bail, P. Trouillas, C. Pouget, G. Habrioux, A.J. Chulia, J.L. Duroux, Anticancer Res. 21, 3949 (2001).

[34] H. Tapiero, K.D. Tew, G.N. Ba, G. Mathé, Biomed. Pharm. Ther. 56, 200 (2002).

[35] S. Burda, W. Oleszek, J. Agric. Food Chem. 49, 2774 (2001).

[36] B.M. Rezk, G.R.M.M. Haenen, W.J.F. van der Vijgh, A. Bast, Biochem. Biophys. Res. Commun. 295, 9 (2002).

[37] M.H. Wu, X.H. Yang, W.D. Zou, W.J. Liu, C. Li, Z. Kristallogr. -New Cryst. Struct. 221, 323 (2006).

[38] C.B. Patil, S.K. Mahajan, S.A. Katti, J. Pharm. Sci. Res. 1, 11 (2009).

[39] M.J.G. Moa, M. Mandado, M.N.D.S. Cordeiro, R.A. Mosquera, Chem. Phys. Lett. 446, 1 (2007).

[40] R.J. Anto, K. Sukumaran, G. Kuttan, M.N.A. Rao, V. Subbaraju, R. Kuttan, Cancer Lett. 97, 33 (1995).

[41] S. Venkateswarlu, M.S. Ramachandra, A.V. Krishnaraju, G. Trimurtulu, G.V. Subbaraju, Ind. J. Chem. Sec. B Org. Med. Chem. 45, 252 (2006).

[42] D.L. Flynn, T.R. Belliotti, A.M. Boctor, D.T. Connor, C.R. Kostlan, D.E. Nies, D.F. Ortwine, D.J. Schrier, J.C. Sircar, J. Med. Chem. 34, 518 (1991).

[43] M. Liu, P. Wilairat, S.L. Croft, A.L.C. Tan, M.L. Go, Bioorg. Med. Chem. 11, 2729 (2003).

[44] J.N. Domínguez, J.E. Charris, G. Lobo, N.G. de Domínguez, M.M. Moreno, F. Riggione, E. Sanchez, J. Olson, P.J. Rosenthal, E-J. Med. Chem. 36, 555 (2001). 
[45] O.V. Yarishkin, H.W. Ryu, J.Y. Park, M.S. Yang, S.G. Hong, K.H. Park, Bioorg. Med. Chem. Lett. 18, 137 (2008).

[46] Y. Xia, Z.Y. Yang, P. Xia, K.F. Bastow, Y. Nakanishi, K.H. Lee, Bioorg. Med. Chem. Lett. 10, 699 (2000).

[47] R. LeBlanc, J. Dickson, T. Brown, M. Stewart, H.N. Pati, D. VanDerveer, H. Arman, J. Harris, W. Pennington, H.L. Holt, M. Lee, Bioorg. Med. Chem. 13, 6025 (2005).

[48] X. Liu, M.L. Go, Bioorg. Med. Chem. 15, 7021 (2007).

[49] G.R. Fenwick, J. Lutomski, C. Nieman, Liquorice, Food Chem. 38, 119 (1990).

[50] J.W. Wegener, H. Nawrath, E-J. Pharmacol. 326, 37 (1997).

[51] D.G. Kang, A.S. Lee, Y.J. Mun, W.H. Woo, Y.C. Kim, E.J. Sohn, M.K. Moon, H.S. Lee, Biol. Pharm. Bull. 27, 366 (2004).

[52] P. Talalay, M.J. De Long, H.J. Prochaska, Proc. Natl. Acad. Sci. USA 85, 8261 (1988).

[53] A.T. Dinkova-Kostova, C. Abeygunawardana, P. Talalay, J. Med. Chem. 41, 5287 (1998).

[54] R. Araya-Maturana, T. Delgado-Castro, M. Gárate, J. Ferreira, M. Pavani, H. Pessoa-Mahana, B.K. Cassels, Bioorg. Med. Chem. 10, 3057 (2002).

[55] S. Yellappa, M. Mahanthappa, E-J. Pharma. Med. Res. 2, 146 (2015).

[56] A. Ryvolová-Kejharová, P. Zuman, J. Electroanal. Chem. Interfacial Electrochem. 21, 197 (1969).

[57] J.P. Zimmer, J.A. Richards, J.C. Turner, D.H. Evans, Anal. Chem. 43, 1000 (1971)

[58] M. Martínez-Cifuentes, B.E. Weiss-López, L.S. Santos, R. Araya-Maturana, Molecules 19, 9354 (2014).

[59] M. Martínez-Cifuentes, R. Salazar, C.A. Escobar, B.E. Weiss-López, L.S. Santos, R. Araya-Maturana, RSC Adv. 5, 50929 (2015)

[60] S. Wawzonek, A. Gundersen, J. Electrochem. Soc. 111, 324 (1964)

[61] I.A. Korshunov, Y.V. Vodzinskii, Zh. Fiz. Khim. 27, 1152 (1953)

[62] V.F. Lavrushin, V.D. Bezuglyi, G.G. Belous, Zh. Obshch. Khim. 33, 1711 (1963)

[63] P. Quintana-Espinoza, C. Yáñez, C.A. Escobar, D. Sicker, R. Araya-Maturana, J.A. Squella, Electroanalysis 18, 521 (2006).
[64] M. Rajendran, M.T. Devi, J. Chem. Bio. Phys. Sci. Sec. A Chem. Sci. 4, 38 (2013).

[65] Z. Cheng, J. Ren, Y. Li, W. Chang, Z. Chen, J. Pharm. Sci. 92, 475 (2003).

[66] I. Vedernikova, E. Proynov, D. Salahub, A. Haemers, Int. J. Quantum Chem. 77, 161 (2000).

[67] M.M. Silva, M.R. Santos, G. Caroço, R. Rocha, G. Justino, L. Mira, Free Radic. Res. 36, 1219 (2002).

[68] J.R. Dimmock, N.M. Kandepu, M. Hetherington, J.W. Quail, U. Pugazhenthi, A.M. Sudom M. Chamankhah, P. Rose, E. Pass, T.M. Allen, S. Halleran, J. Szydlowski, B. Mutus, M. Tannous, E.K. Manavathu, T.G. Myers, C.E. De, J. Balzarini, J. Med. Chem. 41, 1014 (1998).

[69] Y. Zhang, X. Guo, E.T. Lin, L.Z. Benet, Pharmacology 58, 147 (1999).

[70] B. Caliskan, A.C. Caliskan, Radiat. Eff. Def. Sol. 172, 398 (2017)

[71] M. Bersohn, J.C. Baird, An Introduction to Electron Paramagnetic Resonance, Benjamin, New York 1966, p. 190.

[72] B. Caliskan, A.C. Caliskan, E. Er, Radiat. Eff. Def. Sol. 171, 440 (2016).

[73] W.A. Pryor, Free Radicals, McGraw-Hill, New York 1966.

[74] D.H. Anderson, P.J. Frank, H.S. Gutowsky, J. Chem. Phys. 32, 196 (1960)

[75] B. Caliskan, A.C. Caliskan, E. Er, J. Mol. Struct 1144, 421 (2017).

[76] N. Cotelle, S. Moreau, P. Cotelle, J.P. Catteau, J.L. Bernier, J.P. Henichart, Chem. Res. Toxicol. 4, 300 (1991)

[77] M.R. Das, H.D. Connor, D.S. Leniart, J.H. Freed, J. Am. Chem. Soc. 92, 2258 (1970)

[78] J. Eloranta, E. Hämäläinen, E. Salo, R. Mäkelä, U. Kekäläinen, Acta Chem. Scand. A 37, 383 (1983).

[79] L. Michaelis, M.P. Schubert, Chem. Rev. 22, 437 (1938).

[80] B. Caliskan, Acta Phys. Pol. A 125, 135 (2014).

[81] B. Caliskan, A.C. Caliskan, R. Yerli, J. Mol. Struct. 1075, 12 (2014).

[82] B. Caliskan, M. Civi, M. Birey, Radiat. Eff. Def. Sol. 161, 313 (2006)

[83] T. Ohnishi, B.L. Trumpower, J. Biol. Chem. 255 3278 (1980) 